\title{
Research on the Coordinated Development Mechanism of supply chain finance among countries under the development of Internet Era
}

\author{
Yong Lan ${ }^{1, a}$, Ning Miao ${ }^{1,2}$, Yan Ya Wang ${ }^{1}$, Ming Yong Feng ${ }^{1}$, Dong Xia Liu ${ }^{1}$ \\ ${ }^{1}$ (Tianjin University of Finance and Economics pearl River College, Tianjin 301811) \\ 2 (School of Management Science and Engineering, Tianjin University of Finance and Economics, Tianjin 300000)
}

\begin{abstract}
This paper studies the international supply chain finance among trading countries under the Internet financial environment. By introducing "One Belt And One Road" and "supply chain finance", this paper analyzes the main supply chain finance models involved in the "One Belt And One Road" strategy, and uses clustering method to analyze and summarize the financial risks of supply chain. The analysis results are obtained through data mining reasoning. On this basis, it mainly uses Internet information technology, big data analysis and other technologies to deal with the risks in the international supply chain, and puts forward constructive suggestions to promote the coordinated development of supply chain finance among countries.
\end{abstract}

\section{Introduction}

In 2013, China put forward the "One Belt And One Road" economic strategy, and the "One Belt And One Road" initiative further strengthened regional economic integration, opened up a new pattern of foreign trade partners, and enhanced the cooperation potential of all countries. With the extensive implementation of the strategy, the globalization of international trade has been accelerated, and China's foreign trade has expanded. The supply chain finance based on the trade background develops rapidly and the supply chain finance mode plays an irreplaceable role in the process of strategy implementation and development.

The One Belt And One Road strategy covers 64 countries and regions on the Eurasian continent. China's investment in the top 10 trading partners reached $\$ 8.45$ billion in 2014 and $\$ 8.81$ billion in 2016. Among them, China's direct investment in Pakistan accounts for 11.5 percent of the total investment of 10 countries. Most of China's investment is concentrated in Southeast Asia. In 2017, China's direct investment in the region reached us $\$ 7$ billion and US $\$ 470$ million respectively, accounting for 84.8 percent of China's total major investment in the 10 countries along the Belt and Road.

Supply chain finance is the professional field of commercial bank credit business, and also the financing channel for enterprises, especially small and mediumsized enterprises. It means that banks provide timely payment loans to suppliers or advance payment and inventory financing services to distributors while providing financing and other settlement financing services to core customers of enterprises. As early as 2006, the supply chain finance model was applied and implemented. Since then, more and more banks began to carry out supply chain finance business, and some large commercial banks began to carry out international supply chain finance business. With the introduction of the comprehensive strategy in 2013, supply chain finance has entered the ranks of international economic partners. Supply chain finance develops continuously and has a broad prospect.

From the perspective of China's financial trading volume, different financing methods and financial models of different countries have an important impact on China's financial trading volume. Different financial models should be adopted for different types of enterprises. Therefore, it is necessary to analyze the supply chain finance mode in financial transactions in major countries.

There are mainly four types of supply chain in the one belt and one way: Accounts receivable financing mode refers to that in the industrial chain, upstream enterprises apply for financing from banks and other financial institutions and transfer or pledge accounts receivable to financial institutions as repayment guarantee. Banks and other financial institutions issue financing to upstream enterprises based on the judgment of the authenticity of the transaction background between upstream enterprises and core enterprises; Confirmed position financing, also known as advance payment financing mode, refers to the downstream enterprises to apply for loan payment from banks and other financial institutions in advance. After examining and approving the loan application, the financial institution shall issue the acceptance draft for the corresponding amount to the core enterprise; Financing warehouse financing mode, also known as chattel pledge

Corresponding author's e-mail: liumm30@chinaunicom.cn 
financing mode, refers to that financial institutions such as banks accept the chattel provided by small and mediumsized enterprises as the pledge, combine the guarantee of core enterprises and the supervision of logistics companies, and provide financing services for small and mediumsized enterprises; $\mathrm{B} 2 \mathrm{C}$ e-commerce platform financing is a new financing mode that has emerged in recent years. Through the processing of high-quality and accurate data such as merchants' basic information and historical information, enterprises can provide supply chain financial services to reputable merchants. These platforms make use of customers' transaction processes and payment records on the platform to identify risks, assess credit lines and then extend credit.

In this paper, distributor repayment risk is selected as the main risk of supply chain finance. Commercial banks conduct credit investigation on distributors, identify distributors with different repayment capacities and allocate credit lines. In addition, according to the repayment risks brought by dealers, data mining technology is used to obtain the characteristics of a group of dealers with low repayment ability, and different financial policies are formulated for different dealers to control and avoid financial risks.

Enterprises in different countries and regions with upstream and downstream links are selected for data mining analysis, and a large number of business data in the business database are extracted, transformed and analyzed for modeling processing, from which key information is extracted to assist business decision-making.

\section{Data and Methods}

First, collect target data. Take software sales companies with software distributors distributed in different provinces and cities as an example. Then carry out precorrelation analysis to collect sales information of some dealers. The attributes include sales location, sales mode, distributor size, etc. However, not all attributes are related to "repayment risk", that is, they are not necessarily the

$$
\mathrm{I}\left(\mathrm{s}_{1}, \mathrm{~s}_{2}\right)=\mathrm{I}(4,8)=\frac{4}{12} * \log _{2} \frac{4}{12}+\frac{8}{12} * \log _{2} \frac{8}{12}=0.918
$$

Then the entropy of different attributes can be calculated by formula (2):

$$
\begin{gathered}
\mathrm{E}(\text { Place })=\frac{2}{12} * \mathrm{I}(2,0)+\frac{3}{12} * \mathrm{I}(0,3)+\frac{2}{12} * \mathrm{I}(1,1)+\frac{2}{12} * \mathrm{I}(1,1)+\frac{3}{12} * \mathrm{I}(0,3)=0.333 \\
\mathrm{E}(\text { Distributor enterprise scale })=\frac{4}{12} * \mathrm{I}(1,3)+\frac{4}{12} * \mathrm{I}(3,1)+\frac{4}{12} * \mathrm{I}(0,4)=0.5406 \\
\mathrm{E}(\text { registered capital })=\frac{7}{12} * \mathrm{I}(2,5)+\frac{5}{12} * \mathrm{I}(2,3)=0.908 \\
\mathrm{E}(\text { Sales way })=0.9045
\end{gathered}
$$

The information gain of each attribute can be obtained by formula (3):

$$
\text { Gain }(\text { Place })=0.918-0.333=0.585
$$

Gain(Distributor enterprise scale $)=0.918-0.541=0.377$

$$
\text { Gain }(\text { registered capital })=0.918-0.908=0.01
$$$$
\text { Gain }(\text { Sales way })=0.918-0.905=0.013
$$ 
According to the information gain measurement method, the attribute information gain of the dealer data set is $0.585,0.377,0.043$ and 0.013 , respectively. Among them, the attribute with high information gain is the best characteristic attribute in a given data set, such as "sales position". On the contrary, the attribute with low information gain means that when the attribute is selected, the situational value of classified information will be maximized, and the accompanying information will be more uncertain, so it has a weak correlation or no correlation. For example, "sales mode" has the smallest information gain and is either weakly correlated or uncorrelated. The minimum information gain threshold can be set to 0.05. For the "Sales Mode" and "Registered Capital" fields, the information gain of 0.013 and 0.01 is less than 0.05 , respectively, and these two fields can be deleted.

\section{Results}

After deleting the attributes of the collected data, the same tuple is merged to obtain the characteristics of a group of dealers with solvency risk, from which we can see the relationship between the characteristics and risk events.

From broad Angle, namely the reimbursement risk of foreign company is obviously higher than that of domestic company. As far as distributor size is concerned, the repayment risk of large and small enterprises is higher than that of small and medium-sized enterprises. Perhaps in software sales, medium-sized businesses are easier to operate than large ones, and small businesses are more risk-resistant.

\section{Disuccsion}

In the process of carrying out supply chain finance business, banks need to develop and perfect the risk assessment model of supply chain finance,Use the Internet information technology and big data analysis application, timely access to real information, in daily operations through the Internet to generate and accumulate data; Carry out big data analysis and set a reasonable commitment rate. By introducing new enterprise background and transaction essence as evaluation factors to improve the operational efficiency of the whole risk management system; Strengthen internal control, set up a special department responsible for post-loan tracking and pledge management. Banks and businesses should strengthen their links. Establish strict operating standards and monitoring procedures to eliminate internal management loopholes and non-compliance risks.

To establish a professional supply chain finance operation team, enterprises and banks should not only master the traditional financing methods and skills, but also possess the knowledge and skills of innovative financing as well as profound practical experience. Each subject should try their best to perfect the relevant legal contract, clarify the rights and interests of each party, and minimize the legal risks.

\section{Conclusion}

Risk control is a compulsory course for financial institutions. In the development process of supply chain finance business, the country is the leading country. International supply chain finance business will continue to develop in depth. The use of descriptive data to identify high-risk dealers can overcome the uncertainty caused by human experience judgment, improve the level of risk management of Chinese financial institutions for international supply chain finance, and make better coordinated development of One Belt And One Road strategy and supply chain finance with the help of Internet technology.

\section{Acknowledgements}

This project was supported in part by The National Social Science Fund of China(15BXW011);Foundation for Humanities and Social Sciences Research Of the Ministry of Education(18YJA880064);Key scientific research projects of Institutions of higher learning in Henan(18A52002); Scientific research project of Municipal Education Commission(2018SK172);Chinese Society of Higher Education scientific Research on higher Education "13th five-year Plan" key project of sports(17TZ008); the Key research projects of Henan higher education and science and technology project of Henan Province (18A520027

172102210107/19A520023)

\section{References}

1. Subject Group of Supply Chain Finance, ChinaEurope International Business School, Shenzhen Development Bank. Supply Chain Finance: New Finance in the New Economy [M]. Shanghai Far East Publishing House, 2009.

2. Li Yixue, Wang Shouyang, Feng Gengzhong's new subject direction: Practice Development and Theory Review of Logistics Finance [U] System Engineering Theory and Practice, 2017, 30 (1):113.

3. Yan Nina, Sun Baowen. Optimal Strategy of Supply Chain Finance under Warehouse Receipt Pledge Financing Model Considering Credit Quota [J]. Systems Engineering Theory and Practice, 2011, 31 (9): 1674-1679.

4. Feng Wei, Cheng Guoqiang. Evaluation of the international community's "one belt and one road" initiative [N]. China economic times, 2016-7-14 (05).

5. Du Hongquan, $\mathrm{Hu}$ Jiexun. Bank Credit Risk Management Based on Supply Chain Financing [J]. Financial Theory and Practice, 2011, (4): 14-16.

6. Zheng Xiazhong, Tao Qing, He Jiaxuan. Research and application of supply chain financing risk analysis model [J]. China Market, 2012, (49): 30-32.

7. Liao Meiling. Study on the Risk Prevention of Supply Chain Financing for Small and Medium-sized Enterprises [J]. Wuhan Finance, 2012, (5): 24-26. 
8. Hofmann E Inventory Financing in Supply Chains A Logistics Service Provider-approach[J]. International Journal of Physical Distribution \& Logistics Management, 2009, 39 (9) : 716-740.

9. Stephens, Scott. The Supply Chain Council and the Supply Cham Operations Reference (SCOR) Model [J].Logistics Spectrum, 2010, 34(3): 16-18.

10. Gustin, D.Emerging. Trends in supply chain finance [J]. World Trade, 2015, 8.

11. David Gustin. Emerging Trends in supply chain finance [J], WORD TRADE,2005(8):52 53.

12. Enrico Camerinelli. Supply chain finance [J]. Journal of Payments Strategy \&Systems, 2009, 3(2): 114-128.

13. Wesley S.Randall, M.Theodore Farris II. Supply chain financing: using cash-to-cashvariables to strengthen the supply chain [J]. International Journal of Physical Distribution\& Logistics Management, 2009, 39(8): 669-689.

14. Zhiqiang Wang, Qiang Wang, Yin Lai, Chaojie Liang, Drivers and Outcomes of Supply Chain Finance Adoption:An Empirical Investigation in China [J].International Journal of Production Economics ,2020,220:107453.

15. Qifeng Yang, Yingying Wang, Yidong Ren, Research on financial risk management model of internet supply chain based on data science,[J].Cognitive Systems Research,2019,56:50-55.

16. Choi, T.-M., S. W. Wallace, and Y. Wang. 2018. "Big Data Analytics in Operations Management." Production and Operations Management. doi:10.1111/poms.12838. [Crossref], [Web of Science ${ }^{\circledR}$ ], [Google Scholar]. 